\title{
Cost stickiness, corporate risk and management shareholding
}

\author{
Zhang Yan $^{1}$ \\ ${ }^{1}$ Beijing Jiaotong University, Beijing, China
}

\begin{abstract}
Normally, the cost stickiness in enterprises further reduces the efficiency of asset allocation and the accuracy of earnings decision, thus aggravating the risk taking. This paper takes Chinese A-share listed companies from 2009 to 2019 as samples to empirically test the impact of cost stickiness on enterprise risk and the moderating effect of long-term incentive mechanism on this impact. The results show that cost stickiness increases corporate risk significantly. Management shareholding further aggravates the impact of cost stickiness on corporate risk. After further analysis, it is found that cost stickiness significantly increases corporate investment risk, meanwhile, cost anti-stickiness also significantly increases corporate risk, and management shareholding also aggravates the impact of cost anti-stickiness. This study further expands the research on the economic consequences of cost stickiness, also provides new ideas for enterprises to control the level of management shareholding to further restrain the degree of cost stickiness.
\end{abstract}

\section{Introduction}

In the context of increasing uncertainty in the current macroeconomic environment and fierce competition in all walks of life, enterprises face the dual challenges of macro environment and operating efficiency. At the same time, a number of studies have found that both the uncertainty of macro environment and the low efficiency of enterprise internal resource allocation are relevant with enterprise cost stickiness, so enterprises have to pay attention to cost management if they want to seek long-term stable development. Cost behavior theory thinks the enterprise cost is positively correlated with the business volume, and the increase in cost with business volume is the same as the decrease in cost with business volume. Under the traditional model, enterprise cost changes as the change of volume mechanical, managerial decision making and behaviors will not affect the law. However, Noreen and Soderstrom challenged to the traditional model, they think that the theory ignored inaccurately the role of managers' cost management, and the costs vary asymmetrically as volumes rise and fall [1]. Anderson 、 Banker and Janakiraman confirmed their conjecture, for the first time named the phenomenon that the increase of cost when business volume rises is greater than the decrease when business volume drops as "cost stickiness" [2]. At present, most domestic relevant studies focus on the existence of cost stickiness and the impact of adjustment costs, managers' optimistic expectations, agency costs, earnings management motivation and other factors on cost stickiness, but there are relatively few studies on the economic consequences of cost stickiness. Meanwhile, most of the existing studies on the economic consequences of cost stickiness focus on the forecast of cost stickiness to earnings and the influence of corporate performance [3], paying less attention to the impact of cost viscosity on enterprise risk.

In fact, in the face of uncertain macroeconomic conditions, managers out of optimistic expectations still believe that the small fluctuations are short-term. Therefore, it is possible for them to make decisions leading to the deviations between enterprise resource change and income change. At the same time, to save adjustment costs, managers will not be willing to reduce resource input immediately when revenue drops [4], so that enterprises will retain too much idle resources. In addition, the existence of agency problem will make the managers pay more attention to their own interests in the overall resource planning, thus increasing the asymmetry between cost and income, reducing the efficiency of enterprise resource utilization, and leading to greater risks in business activities. Therefore, it is necessary to study the specific impact of cost stickiness on enterprise risk.

Furthermore, many scholars have found that managerial ownership, as a long-term incentive mechanism, will bring both the convergence of interest effect and the trench defense effect to enterprises. Under the former, the granting of equity to managers make them take the long-term interests of enterprises as the decisionmaking target. Therefore, they may make more strategic investments. However, due to the inherent characteristics, the cost cannot be reduced with the decrease of income, thus increasing the stickiness of cost. Under the later theory, the increase of managerial ownership will increase their motivation and ability to conduct self-interested behaviors, thus exacerbating the agency problem and increasing cost asymmetry. Therefore, will management shareholding increase the negative impact on corporate risk due to the increased stickiness of costs?

Based on the above background, this paper mainly 
studies the relationship between cost stickiness and enterprise risk, and whether management shareholding can have a moderating effect on this relationship. Specifically, this paper takes China's a-share listed companies from 2011 to 2019 as sample, on the basis of measuring the level of enterprise cost stickiness, the influence of cost stickiness on enterprise risk is studied, as well as the enhancement effect of management shareholding, and then introduced the investment risk and cost anti-stickiness to do further analysis, and then do the robustness tests of the results, summarizing the research conclusion.

This paper may make the following two contributions :(1) To expand the research perspective of economic consequences of cost stickiness in the existing literature. (2) To find out the reasons for deepening the degree of cost stickiness, and provide new ideas for enterprises to solve the problem of cost stickiness.

\section{Hypotheses development}

\subsection{Influence mechanism of cost stickiness and enterprise risk}

The cost stickiness makes the business risk of the enterprise increase. American public companies have been found for the first time that they have expenses stickiness [5]. After that, a large number of research results show that industry attributes and asset characteristics are important reasons that lead to the problem of cost stickiness. With the economic fluctuation, the asymmetry between cost and income increases, reflecting the low resource allocation efficiency of enterprises, which in turn makes it difficult for enterprises to maintain their business activities under the uncertain macro environment, thus increasing their business risks. The specific reasons are as follows: First, according to the cost adjustment theory, because the cost of the enterprise's downward adjustment commitment resources is higher than its upward adjustment commitment resources [6]. Therefore, when the sales volume changes greatly, the adjustment cost of enterprises is higher due to the change of their cost structure. [7], which would increase the risk of enterprises. At the same time, when the enterprise capital intensity is high, the asset specificity is strong, changing the assets using way will bring bigger resource loss, enterprises may not immediately reduce resource input when revenue drops in order to control the adjustment costs [8], and reverse increase the idle resources of enterprises, reduce the resource allocation efficiency of the enterprise, increase the operating risk.

In addition, the "empire building" motivation of managers will deepen the agency problem, such as increasing excessive resource input when the business income of the enterprise rises, while when declining too few resources when income reduces, making the amount and structure of resources used by enterprises do not match with the macro conditions [9], which contributed to the asymmetry of cost and income, the allocation rate and utilization rate of enterprise resources decrease and the operation risk increases.
Cost stickiness not only deepens business risk, but also enhances decision-making risk. On the one hand, according to the theory of managers' optimistic expectations, managers usually expect the future sales to be higher than the current sales. Therefore, when the sales volume of enterprise declines, managers may be unwilling to reduce the input of cost resources, in order not to bear the higher adjustment costs caused by it. When the sales volume of enterprises increases, managers will be more willing to increase the input of cost resources, so as to lay a solid foundation for the vigorous development of enterprises in the future. The optimistic expectation of the management intensified the degree of cost stickiness [10], reduced decision-making ability and increased enterprise risk.

On the other hand, It was proved that cost asymmetry brings negative impact to the traditional forecast model of earnings level, and accurate forecast of earnings determines whether the managers can make accurate decisions [11]. Therefore, cost stickiness blurs the managers' judgment and estimation of enterprises' operating conditions, which leads to the possibility of making resource allocation decisions that damage the development of the enterprise and increase the decisionmaking risk.

Based on the above analysis, it can be seen that the uncertainty of macro economy and the specificity of enterprise assets will make the enterprise do not reduce cost resources at the same proportion in order to save adjustment costs when income drops, thus reducing the enterprise's resource allocation efficiency and increasing the enterprise's operating risk. At the same time, the optimistic expectation of the management aggravates the degree of cost stickiness, which also significantly reduces the accuracy of mangers' earnings decision-making, thus increasing the decision-making risk. Based on this, hypothesis 1 is proposed.

Hypothesis 1. The higher the degree of cost stickiness, the greater the enterprise risk.

\subsection{Maintaining the Integrity of the Specifications}

According to agency theory, due to the separation of ownership and management in corporations, the objectives of managers and shareholders are not aligned, out of self-interest maximization, management may have self-interest behavior while allocating resources, which makes the allocation of enterprise resources and the actual operating conditions do not match. Management shareholding, as a long-term incentive mechanism, is often used to alleviate the agency problem. Management shareholding aims to link the interests of the management and the enterprise by granting shares to the managers, so as to reduce the opportunism behavior of the management and reduce the agency cost.

According to the interests of the convergence theory, granting shares to managers help to achieve the sharing and risk-sharing with the interests of the shareholders, thus bring more strategic investment for enterprises, which may cause the enterprise income reduce in the short term, but the rigidity characteristics of cost will make 
corresponding cost reduce with income less likely, resulting in the adjustment cost increase, aggravating cost stickiness. In addition, the equity incentive also brings trench defensive effect, with managers' ownership rise, empire building motivation increases, managers can make more decisions that is beneficial to their personal interests but detrimental to the benefits of enterprises, aggravating problem of agency, and the management of optimism will not cutting costs according to the decrease of income, thus increase the cost of asymmetry. 2:

Based on the analysis, this paper proposes hypothesis

Hypothesis 2. Management ownerships will aggravate the positive correlation between cost stickiness and corporate risk.

\section{Sample and variable measurement}

\subsection{Abbreviations and Acronyms}

This paper takes A-share listed companies in China from 2011 to 2019 as research samples. In order to obtain more robust variables, the data of abnormal enterprises and financial enterprises were eliminated. At the same time, in order to eliminate the influence of extreme values, all variables were reduced $(1 \%, 99 \%)$. The data used in this paper is mainly from the CSMAR database. The software used is Stata15.0.

\subsection{Variable definitions}

1) Cost stickiness: The Weiss model proposed by Weiss can use the quarterly financial data of enterprises to calculate the cost stickiness level of listed companies in each fiscal year [12]. Therefore, Weiss model is adopted in this paper to quantify the cost stickiness level of sample companies.

2) Enterprise risk: Using the methods that been used by domestic and foreign scholars for reference, this paper selects the volatility of accounting earnings of enterprises as the measurement index of enterprise risk, namely the rolling standard deviation of enterprise ROA from $t$ to $t+2$ years to measure Risk [13].

3) Control variables: this paper draws on previous research results, selecting the following variables as the main control variables.

\subsection{Model design}

1) Model of cost stickiness: Weiss model is used to calculate the year-end cost stickiness level of each sample company, as shown in model (1)

$$
\text { Stick } y_{i, t}=\log \left(\frac{\Delta \operatorname{Cost}}{\Delta \text { Sale }}\right)_{i, \omega_{1}}-\log \left(\frac{\Delta \operatorname{Cost}}{\Delta \text { Sale }}\right)_{i, \omega_{2}} \text {. }
$$

2) Model of the relationship between cost stickiness and enterprise risk: According to the cost stickiness variable obtained in model (1), it is taken as independent variable to establish model (2) to test the relationship between cost stickiness and enterprise risk.
Risk $=\beta_{0}+\beta_{1}$ Sticky $+\beta_{2}$ Controls $+\sum$ year + $\sum$ Industry $+\varepsilon$. (2)

3) Model of the influence of management shareholding on the following relationship: Based on model (2), the model (3) is constructed by introducing the variables of management shareholding and the crossmultiplication term of management shareholding and cost stickiness:

Risk $=\beta_{0}+\beta_{1}$ Sticky $+\beta_{2}$ Stockhold $\times$ Sticky + $\beta_{3}$ Stockhold $+\beta_{4}$ Controls $+\sum$ year $+\sum$ Industry + $\varepsilon$.(3)

\section{Empirical results}

\subsection{Descriptive statistics}

Table 2 is the descriptive statistical results of the main variables. As can be seen from Table 2, the average value of enterprise cost stickiness is -0.034 , indicating that the cost reduction margin when the operating revenue drops is smaller than the cost increase margin when the operating revenue rises, thus proving that listed companies basically have cost stickiness. In addition, the standard deviation of enterprise size is 1.269 , indicating that the size and average strength of listed companies in China vary greatly, while the average equity concentration ratio of enterprises is about $56.8 \%$, indicating that most listed companies have a high equity concentration ratio.

Table1. Descriptive statistics

\begin{tabular}{|c|c|c|c|c|c|c|}
\hline Variables & $\mathbf{N}$ & Mean & Median & $\begin{array}{c}\text { Std } \\
\text { Dev }\end{array}$ & Max & Min \\
\hline Risk & 14000 & 0.036 & 0.027 & 0.036 & 0.002 & 0.233 \\
\hline Sticky & 14000 & -0.034 & -0.017 & 0.415 & -1.642 & 1.281 \\
\hline Stockhold & 14000 & 0.055 & 0.000 & 0.122 & 0.000 & 0.574 \\
\hline Size & 14000 & 22.200 & 22.040 & 1.269 & 19.650 & 26.050 \\
\hline Lev & 14000 & 0.441 & 0.436 & 0.210 & 0.053 & 0.916 \\
\hline
\end{tabular}

Table 3 shows the Pearson correlation analysis results of the main variables in this paper. The data in Table 3 show that enterprise cost stickiness is positively correlated with enterprise risk, which is inconsistent with the assumptions of this paper. At the same time, the correlation coefficient between all variables in the model is less than 0.5 , indicating that there is no strong correlation between variables.

Table2. Correlation matrix

\begin{tabular}{|c|c|c|c|c|c|}
\hline Variables & Risk & Sticky & Stockhold & Size & Lev \\
\hline Risk & 1 & & & & 1 \\
\hline Sticky & $\mathbf{0 . 0 0 7 0 0}$ & 1 & & & 0.00700 \\
\hline Stockhold & $\begin{array}{c}- \\
0.019 * *\end{array}$ & $\begin{array}{c}- \\
0.022 * * *\end{array}$ & 1 & & $\begin{array}{c}- \\
0.019 * *\end{array}$ \\
\hline Size & $\mathbf{0 . 0 1 4 0}$ & $-\mathbf{0 . 0 0 1 0 0}$ & $-0.263 * * *$ & 1 & 0.0140 \\
\hline Lev & 1 & & & & 1 \\
\hline
\end{tabular}

\subsection{Cost stickiness and enterprise risk}

In this paper, model (2) is used to test the relationship between enterprise risk and cost stickiness of listed 
companies in China. The regression results are shown in Table 4. It can be seen that the coefficient of cost stickiness is negative at the significant level of $5 \%$. In other words, the greater the degree of cost stickiness of an enterprise, the higher the risk of the enterprise will be. In addition, if the coefficient of sticky is negative, the enterprise has cost stickiness, and the smaller the value is, the greater the degree of cost stickiness will be.

From column (1), the results also can be seen that the capital structure and enterprise risk is negatively correlated. Showing that the higher the enterprise assetliability ratio is, the greater the risk of the enterprise. However, the enterprise size is significantly positively correlated with enterprise risk at $1 \%$, indicating that the larger the enterprise size, the smaller the enterprise risk.

\subsection{Cost stickiness, management shareholding and enterprise risk}

It can be seen that the management shareholding is significantly negative at the level of $1 \%$, with a coefficient of -0.0078 . It means that the higher the management shareholding is, the lower the enterprise risk will be. The coefficient of cross multiplication term is significantly negative at the level of $10 \%$, which is -0.0106 , indicating that the increase of management shareholding ratio aggravates the negative influence of cost stickiness on enterprise risk. Therefore, hypothesis 2 is verified.

From column (2) ,we can also find that after introducing the management equity, the capital structure is still negatively related to the enterprise risk significantly, at the same time, the enterprise size is significantly positive correlation with the enterprise risk, the other factors that didn't listed are also stay the same, that is, the relationship between the capital structure, profitability, ownership concentration, listed years, proportion of independent directors, enterprise size and property right structure and enterprise risk will not change significantly due to the variable of management shareholding.

Table3. Regression results

\begin{tabular}{|c|c|c|}
\hline \multirow{2}{*}{ Variables } & \multicolumn{2}{|c|}{ coefficient } \\
\cline { 2 - 3 } & $(\mathbf{1})$ & (2) \\
\hline \multirow{2}{*}{ Sticky } & $-0.0016^{* *}$ & -0.0012 \\
& $(-2.20)$ & $(-1.55)$ \\
\hline Sticky $\times$ & & $-0.0106^{*}$ \\
Stockhold & & $(-1.66)$ \\
\hline \multirow{2}{*}{ Stockhold } & & $-0.0078^{* * *}$ \\
& & $(-2.73)$ \\
\hline \multirow{2}{*}{ Size } & $-0.0081^{* * *}$ & $-0.0082^{* * *}$ \\
& $(-24.56)$ & $(-24.70)$ \\
\hline \multirow{2}{*}{ Lev } & $0.0312^{* * *}$ & $0.0311^{* * *}$ \\
& $(18.37)$ & $(18.26)$ \\
\hline
\end{tabular}

\subsection{Further analysis}

1) Cost anti-stickiness and enterprise risk: Cost antistickiness is opposite to the concept of cost stickiness, that is, the magnitude of cost reduction when business volume drops is greater than that of cost increase when business volume rises [14]. It was found that, enterprise risks will be enhanced not only by cost stickiness, but also by the inefficient disposal of excess assets caused by cost antistickiness [1].

2) Cost stickiness and investment risk: In order to further study how cost stickiness affect enterprise risk, this paper choose the investment risk of enterprise risk as explained variable, because investment activity to a certain extent, decided whether enterprises' assets can be effectively run, affect the competition ability of the enterprise, thus affecting the asymmetry relationship between cost and income, so companies overinvestment and underinvestment behavior will affect the degree of cost stickiness. As a high-risk investment, innovation expenditure of enterprises is an important indicator to measure investment risk.

\subsection{Robustness test}

In order to further test the robustness of the results, this paper makes an empirical test from the following aspects: 1. Replace the core variable test. Change the measurement method of enterprise risk and use the standard deviation of operating income as the alternative variable of enterprise risk to test. 2. Change the sample size. Due to the variability of samples, the test results are affected. In this paper, the samples of listed companies in manufacturing industry are specially selected for testing to observe whether the conclusions are consistent. Under the above test methods, the conclusions of this paper are consistent all the time, so it is considered that the results of this paper have a certain robustness.

\section{Conclusion}

Based on the financial data of all non-financial a-share listed companies in China from 2011 to 2019, this paper empirically examines the relationship between cost stickiness and corporate risk and the enhancement effect of management shareholding on this relationship, draws the following conclusions: (1)The greater the degree of stickiness, the greater the enterprise risk; (2) Management shareholdings will significantly increase the positive effect of cost stickiness on enterprise risk; (3) Cost counter-stickiness will significantly increase enterprise risks, and management shareholdings will aggravate this positive correlation; (4) Cost stickiness will significantly increase enterprise investment risk, and management shareholdings will aggravate the positive effect.

According to the research results of this paper, the mismatch between income and cost is referred to as enterprise risk, and the equity incentive behavior will play a role in aggravating the economic consequence of cost stickiness. Therefore, in order to reasonably arrange cost management, enterprises should deeply understand economic consequences of cost stickiness and take corresponding measures to reduce the impact of relevant governance mechanisms that are not conducive to the sustainable development of enterprises. 


\section{References}

1. Noreen E., Soderstrom N., 1997. The Accuracy of Proportional Cost Models: Evidence from Hospital Service Departments. Review of Accounting Studies, 2:89 -114.

2. Anderson, M. C., R. D. Banker, S. N., Janakiraman. 2003. Are Selling, General, and Administrative Costs "Sticky"?[J]. Journal of Accounting Research,41 (1):47-63.

3. Anderson S., Lanen W. 2007. Understanding Cost Management: What Can We Learn From the Evidence on "Sticky Costs"? Working paper.

4. Banker R., Chen L. 2006a. Labor Market Characteristics and Cross-Country Differences in Cost Stickiness. Working paper.

5. Banker R., Byzalov D., Plehn-Dujowich J. 2010a. Sticky Cost Behavior: Theory and Evidence. Working paper.

6. Kong Yusheng, Zhu Naiping, Kong Qinggen. Research on Cost Stickiness: Empirical Evidence from Chinese listed companies [J]. Accounting Research, 2007 (11):58-65.

7. Cannon, J. N. 2014. Determinants of 'Sticky Costs': An Analysis of Cost Behavior using United States Air Transportation Industry Data. Accounting Review, 89 (5):1645-1672.

8. Weiss, D. 2010. Cost Behavior and Analysts' Earnings Forecasts[J]. Accounting Review, 85 (4) : 1441-1471. 